\title{
TRANSPORT ASPECTS OF INTERNATIONAL COLLABORATION IN CENTRAL EAST EUROPEAN COUNTRIES
}

\begin{abstract}
Adam Rajca
Abstract The article is devoted to the development of economic and organizational aspects of international transportation system, and international transport corridors particularly, which is the very important constituent of successful international economic relations between countries and assists activation of international ties between West\&East Europe and Asia.
\end{abstract}

Keywords: international economy, global marketing, transcontinental transportation system, international transport corridors, international economic collaboration 